\title{
Acción colectiva y representación gremial: el caso de la Sociedad de Agricultores y Ganaderos del Valle del Cauca, Colombia, 1940-2002
}

\section{Collective action and business representation: the case of Sociedad de Agricultores y Ganaderos del Valle del Valle del Cauca, Colombia, 1940-2002}

\author{
Julio Cesar Zuluaga ${ }^{1,} *$ (iD 0000-0003-2860-145X
}

Víctor Cobo ${ }^{2}$ iD 0000-0003-0591-1770

\footnotetext{
${ }^{1}$ Pontificia Universidad Javeriana, Cali, Colombia.

${ }^{2}$ Facultad Latinoamericana de Ciencias Sociales, Quito, Ecuador.
}

*Correspondencia: julio.zuluaga@javerianacali.edu.co

Resumen. Los empresarios crean asociaciones gremiales para coordinar la acción colectiva frente a otras organizaciones y grupos de interés, además de proveer bienes y servicios a sus afiliados. Este artículo explora la evolución de la Sociedad de Agricultores y Ganaderos (SAG) del Valle del Cauca desde su creación en 1937, así como los roles y funciones que asumió como representante de los intereses agrícola-ganaderos en el contexto colombiano. Con base en la revisión de actas, correspondencia, informes de presidencia y editoriales de la Revista Agrícola y Ganadera, este análisis revela la posición de la SAG frente a tres proyectos: la misión del Banco Mundial liderada en 1950 por Lauchlin B. Currie; la aplicación del programa de

CÓMO CITAR: Zuluaga, J. C. y Cobo, V. (2021). Acción colectiva y representación gremial: el caso de la Sociedad de Agricultores y Ganaderos del Valle del Cauca, Colombia, 1940-2002. América Latina en la Historia Económica, 28(1), 1-30. DOI: 10.18232/alhe.1063 
inversiones propuesto por David Lilienthal en 1954; y la Ley 135 de 1961 o Ley de Reforma Agraria. Con ello, se demuestra que el comportamiento de la SAG estuvo determinado por la lógica de la influencia y la lógica de los servicios.

Palabras clave: asociaciones; gremios; agricultura; política agrícola; historia empresarial; Colombia.

Abstract. Entrepreneurs build business associations to organize collective action and provide goods and services to their members. This article explores the origin and evolution of the Sociedad de Agricultores $y$ Ganaderos (SAG) del Valle del Cauca and determines their role and function in the agency of agricultural interests in the Colombian economy. Based on board minutes, correspondence, presidency reports and the Revista Agrícola y Ganadera' editorials, we analyze the position of the sag in three projects: the World Bank mission led in 1950 by Lauchlin B. Currie; the application of investment program by David Lilienthal in 1954; and the Law 135 of 1961 or Agrarian Reform Law. Based on this analysis, we argue that the Logic of Influence and Logic of Services drove the behavior of the SAG.

Key words: business associations; guilds; agriculture; agriculture politics; business history; Colombia.

JEL: N56; N96.

Recibido: 14 de febrero de 2019.

Aceptado: 19 de septiembre de 2019.

Publicado: 16 de julio de 2020.

Organismo patrocinador: Pontificia Universidad Javeriana.

\section{INTRODUCCIÓN}

La historiografía económica sostiene que los empresarios crean asociaciones gremiales para representarse frente a otras organizaciones y grupos de interés, así como facilitar la acción colectiva frente al Estado (Lanzalaco, 2008; Schneider, 2002, 2004). Este tipo de organizaciones ofrecen a sus miembros un espacio para reunirse e intercambiar puntos de vista sobre aspectos cruciales de su sector, aprender y difundir nuevas tecnologías, explorar posibles oportunidades de negocio, proveer bienes y servicios críticos para el desarrollo de sus afiliados, además de ser mecanismos de coordinación para afrontar cambios y presiones del entorno regional (Medina, 2016). La importancia de estas organizaciones contrasta con la poca investigación sobre su comportamiento e incidencia en la economía colombiana del siglo xx. A pesar de los diversos estudios sobre gremios en Colombia 1 -donde destacan los de Bejarano (1985), Machado y Samacá (2000), Rettberg (2001a; 2001b; 2003), Sáenz (1992) y Urrutia (1983)-, poco se han explorado y evaluado los roles y funciones que estas organizaciones han tenido en el desarrollo empresarial (Zuluaga, 2009; 2012).

Las asociaciones de intereses de negocio, comúnmente conocidas como asociaciones gremiales, pueden ser entendidas al tener en cuenta las posibles formas de acción de los empresarios (Lanzalaco, 2008). Por ejemplo, los empresarios pueden actuar de manera individual -como gerentes o propietarios- o colectivamente coordinados a través de coaliciones informales -relaciones de

\footnotetext{
${ }^{1}$ Losada (2000) presenta una completa y detallada revisión de los estudios sobre gremios empresariales en Colombia.
} 
amistad y/o parentesco- o formales - carteles, alianzas estratégicas, clubes, cooperativas o asociaciones-. Así, un aspecto fundamental es entender cuáles son los factores que determinan la evolución, comportamiento e impactos de las asociaciones gremiales.

El comportamiento de los gremios es muy variado, fungen como asociaciones de empleadores cuando interactúan con trabajadores y sindicatos en el mercado de trabajo, o como asociaciones de productores $\mathrm{u}$ hombres de negocios en sus relaciones con clientes, proveedores, políticos y otras organizaciones en los mercados de capitales y/o productos. En ambos casos, estudios previos sostienen que los empresarios tienen diferentes motivaciones, deseos y capacidades que configuran dos lógicas diferentes de acción de las asociaciones gremiales (Dixon, 2006). De un lado, los gremios pueden estar orientados hacia una lógica de los servicios: estrategia orientada hacia la provisión de bienes y/o servicios al conjunto de asociados, conocidos comúnmente como bienes club. Por otro lado, los gremios pueden focalizar sus recursos hacia una lógica de la influencia: estrategias determinadas por la necesidad de obtener representación y poder de negociación frente a otros grupos de interés (Estado, proveedores, clientes o trabajadores).

La evidencia histórica en el ámbito internacional ha mostrado que, dadas las restricciones de recursos y los problemas de agencia y coordinación, una de las dos lógicas puede predominar u opacar a la otra (Lanzalaco, 1992; Streeck, Grote, Schneider y Visser, 2006; Traxler y Huemer, 2007; Waarden, 1992). La explicación es que los beneficios de la representación -resultado de la lógica de la influencia - no siempre son claros a los miembros de las asociaciones gremiales, además que la provisión de bienes colectivos - resultado de la lógica de los servicios- enfrenta muchas barreras como problemas de apropiabilidad y coordinación, a la par de un alto potencial de conflicto y conducta tipo free-rider entre los asociados. En este sentido, en la literatura teórica y empírica no es claro cuál es el comportamiento que predomina en las asociaciones gremiales.

Con esta línea de ideas, este trabajo tiene como objetivo analizar los roles y funciones que la Sociedad de Agricultores y Ganaderos (en adelante SAG) del Valle del Cauca ha desempeñado en el desarrollo agrícola y con ello determinar cuál ha sido la lógica prevaleciente de acción. Por ello, se concentra en el examen de las decisiones y temáticas documentadas en 134 actas de la junta directiva durante el periodo 1989-2002, en el análisis de 853 documentos y correspondencia, así como la revisión de 227 editoriales de la Revista Agrícola y Ganadera, órgano de divulgación de la asociación.

Como resultado de este análisis, es posible argumentar que la sAG se ha movido entre las motivaciones, deseos y capacidad de acción basada en la lógica de influencia y la lógica de servicios. En particular, la evidencia recogida fundamenta la hipótesis que la lógica de influencia ha sido la estrategia predominante. Esto como consecuencia de la configuración de un modelo institucional entre 1930 y 1990 que incentivó comportamientos rentistas, estrategias de influencia y, a veces, captura del Estado a través de la creación de entidades gremiales. Asimismo, los cambios drásticos que sufrió el sector agropecuario a finales de la década de 1980 y principios de 1990, caracterizados por un periodo de reorganización de las políticas e instituciones encargadas de regular las dinámicas de producción y del mercado agropecuario en el país, ayudan a entender la pérdida de influencia de las asociaciones gremiales en la economía política nacional.

Primeramente, se revisa la literatura y se plantea el marco de análisis propuesto; luego, se señala la metodología, fuentes de información y el procedimiento de análisis de la información para así reconstruir el origen y evolución de la asociación; y finalmente, presentar las coyunturas históricas que dan lugar a la discusión de los resultados, así como las conclusiones y los aportes de este trabajo a la historiografía empresarial y de los gremios en Colombia. 


\section{ROLES, FUNCIONES Y LÓGICAS DE LAS ASOCIACIONES GREMIALES}

Este estudio integra los aportes de Bennett (1995; 1999), Ocasio (1997), Schmitter y Streeck (1981) y Simon $(1948 ; 1972)$, además del reciente caso de estudio sobre asociaciones de negocio desarrollado por Dixon (2006) para Inglaterra, y por Waarden (1992) para Holanda. Partiendo del concepto clásico de la lógica de la acción colectiva -propuesto por Olson (2003) en 1965 y desarrollado por Offe y Wiesenthal (1980)- planteamos que las asociaciones de negocios están determinadas por dos lógicas potencialmente conflictivas: la lógica de servicios -llamada originalmente lógica de la membresía por Schmitter y Streeck- y la lógica de la influencia. La primera se relaciona con la provisión de bienes específicos a los miembros, mientras que la segunda se relaciona con las actividades de representación de un colectivo de empresas y empresarios, donde la asociación habla y actúa por todos o la gran parte de sus miembros (Bennett, 1999).

$\mathrm{El}$ análisis de las asociaciones gremiales a través de estas dos lógicas es relevante porque en un mundo de racionalidad limitada e incertidumbre (Simon, 1972), la capacidad de los empresarios para identificar los problemas de organización y hacer frente a las presiones del entorno de negocios enfrenta numerosos obstáculos que precisan de instrumentos de coordinación y análisis de la información. En este sentido, los gremios pueden concebirse como una respuesta organizacional que los empresarios desarrollan para lidiar con los problemas de coordinación y la incertidumbre del entorno de negocios. Esta idea se fundamenta en los planteamientos clásicos de la Teoría Organizacional que entienden a las organizaciones como estructuras de toma de decisiones que reducen la incertidumbre (March y Simon, 1958; March, 1962; Ocasio, 1997) y como coaliciones de poder (March, 1962; Pfeffer y Salancik, 2003) que permiten agenciar metas, objetivos y demandas de determinados grupos de interés, en particular de asociaciones de empresarios (Schneider, 2002). El predominio de alguna de estas dos lógicas determina los marcos cognitivos y las estructuras de decisión que seleccionan/imponen prioridades y asignan los esfuerzos y recursos del gremio.

Así, las asociaciones gremiales enfrentan una serie de restricciones en relación con la selección de los planes de acción y las estrategias a seguir que satisfagan la creación de valor en beneficio de sus afiliados (Simon, 1948; 1956), mismas que están condicionadas por las motivaciones, deseos y capacidad de las asociaciones de involucrarse en alguna de las dos lógicas de acción colectiva, por las características del ambiente de negocios, así como por la complejidad y velocidad de los cambios en el entorno institucional y la dinámica de los mercados.

\section{Metodología}

Este trabajo adoptó una perspectiva abductiva en la que, a través del dialogo constante entre concepto y dato empírico, se realizó el análisis de la información (Thompson, 2002). Aunque se realizó un análisis preliminar de tipo cuantitativo basado en análisis de frecuencias, la metodología principal fue cualitativa, particularmente bajo la metodología de estudio de caso (Eisenhardt, 1989; Eisenhardt y Graebner, 2007). Esto permitió por medio de la interpretación de la información construir una narrativa explicativa que da cuenta de la evolución de las lógicas de la SAG a lo largo del tiempo.

El procedimiento de análisis de las actas consistió en la lectura y codificación de la información de manera inductiva e independiente por cada uno de los investigadores, para luego discutir en conjunto las similitudes e inconsistencias en la codificación de todas las decisiones y temas abor- 
dados en la junta directiva. De este análisis emergieron 15 categorías que corresponden a un total de 768 unidades de información ${ }^{2}$ Este primer examen permitió determinar una hipótesis provisional: el comportamiento de la SAG se orienta fundamentalmente hacia estrategias de influencia sobre el diseño de la institucionalidad agrícola y búsqueda de privilegios con el gobierno local y nacional.

Posteriormente, se revisó y analizó la información de correspondencia, informes de presidencia y editoriales de la Revista Agrícola y Ganadera con el objetivo de reconstruir la evolución del gremio en relación con eventos o coyunturas que estuvieran relacionados con el despliegue de estrategias orientadas hacia ambas lógicas (de la influencia o de los servicios) y problematizadas en la revisión de literatura. Este proceso de interpretación permitió identificar y analizar a profundidad tres coyunturas históricas críticas en el despliegue de estrategias de la SAG que determinaron sus concepciones sobre el desarrollo agrícola regional: la misión del Banco Mundial liderada en 1950 por Lauchlin B. Currie; la aplicación del programa de inversiones propuesto por David Lilienthal en 1954; y la Ley 135 de 1961 o Ley de Reforma Agraria.

Finalmente, para reconstruir los orígenes del gremio se revisó la información de los números publicados entre 1940 y 1965 de la Revista Agrícola y Ganadera, órgano de divulgación de la SAG. Esta fuente contiene artículos, editoriales y, principalmente, los informes anuales de los presidentes de la Sociedad en los que se relacionan y describen las principales ejecutorias de la asociación. En este sentido, la Revista Agrícola y Ganadera fue nuestra principal fuente de información. El gremio publicó entre 1937 y 1967 un total de 278 ediciones. Finalmente, es necesario aclarar que el Comité de Ganaderos del Valle participó oficialmente en ella a partir de 1947 y hasta 1963, año en que ambas entidades desaparecen para conformar un solo gremio denominado Sociedad de Agricultores y Ganaderos (sAG) del Valle del Cauca.

\section{La Sociedad de Agricultores y Ganaderos, Roles y decisiones, 1940-2002}

Un análisis general sobre las decisiones de la junta directiva de la SAG sugiere que ha predominado la lógica de la influencia, lo cual no implica que la lógica de los servicios haya estado ausente. El análisis de 134 actas, del periodo 1989-2002, revela las decisiones, problemas y temáticas en que los dirigentes centraron su atención, mismas que a lo largo del tiempo configuraron las dos lógicas de acción que son el interés de esta investigación. Al respecto, las decisiones relacionadas con la lógica de la influencia casi duplican a la de los servicios (véase cuadro 1). De las 15 categorías emergentes, las estrategias de intervención institucional y de obtención de beneficios de entidades o instituciones tienen los más altos valores para todo el periodo. Esto nos permite avanzar hacia un análisis detallado de los roles y funciones que la SAG ha tenido en el desarrollo agropecuario, en particular, la materialización de determinados intereses y visiones sobre el desarrollo agrícola en tres coyunturas históricas entre las décadas de 1940 y 1960.

\footnotetext{
${ }^{2}$ En la construcción de los datos se definió como unidad de información cada una de las decisiones y/o temas tratados en las actas de junta directiva. En el anexo 1 se muestran las categorías y la descripción-definición construida. La base de datos se compone de 768 unidades de información organizadas por categorías, la cual puede solicitarse a los autores de este artículo.
} 


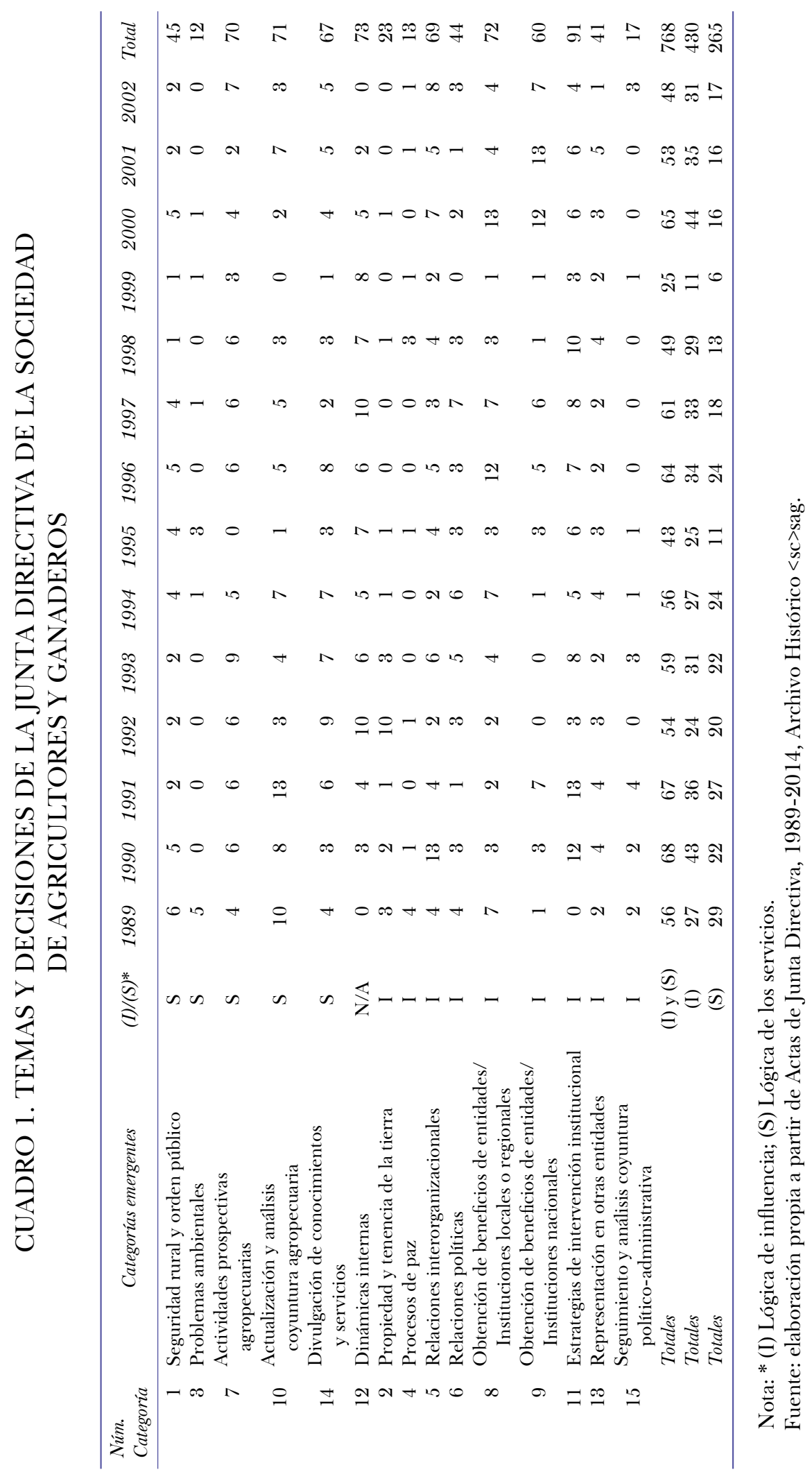


Inicios y lógicas de acción de la Sociedad

Aunque Bejarano (1985) menciona el intento de organización de una Sociedad de Agricultores en Buga, la existencia de otra Sociedad en Cali hacia mediados de la segunda década del siglo xx, y la Ley 74 de 1926 que establece filiales de la Sociedad de Agricultores de Colombia (SAC) en las capitales de departamento ${ }^{3}$ es solo a partir de 1937 que tenemos registro de actividad plena y continua de una asociación de esta naturaleza en el Valle del Cauca 4 En efecto, la Sociedad de Agricultores reunía a empresarios de la región dedicados a la ganadería e interesados en la agricultura comercial (Collins, 2018).

La Sociedad de Agricultores se propuso actuar como interlocutora entre los intereses de un empresariado agrícola en formación y las instancias de poder local, regional y nacional. Así, al amparo de la Sociedad de Agricultores de Colombia, se constituyó desde sus inicios como una coalición formal de individuos con interés en desarrollar la producción agropecuaria en la región, lo que en la práctica le permitió ser la máxima entidad representativa del sector agropecuario en el Valle del Cauca al convertirse en cuerpo consultivo del gobierno departamental (Bejarano, 1985, p. 144).

La alta diversificación y participación en actividades políticas y públicas de los empresarios que conformaron la asociación hace difícil diferenciar entre un individuo y un sector o actividad predominante. Sin embargo, el perfil de algunos de sus miembros fundadores permite determinar y distinguir representaciones específicas de intereses particulares en la asociación. Por ejemplo, los cafeteros tuvieron representación por medio de Alejandro Garcés Patiño, Antonio Moncaleano, Mariano Córdoba y Adán Uribe Restrepo; los ganaderos a través de Abraham Domínguez Vásquez, Ángel María Castro Borrero y personajes como Pablo Borrero Ayerbe o Ciro Molina Garcés, quiénes tenían una fuerte influencia sobre la dirigencia política y el sector agropecuario desde el gobierno departamental.

Aunque no disponemos de los primeros números de la Revista Agrícola y Ganadera editados en 1937 y 1938, en los que seguramente se encontrarían expresadas las motivaciones y razones que llevaron a este grupo de hacendados y ganaderos a asociarse, es posible inferir a partir de algunas de sus preocupaciones plasmadas en la revista $-\mathrm{y}$ de la lectura del contexto social y político de finales de la década de 1930 e inicios de 1940- la apremiante necesidad de contar con una entidad gremial regional.

Desde su creación, la SAG se condujo entre una lógica dictada por la necesidad de construir una representación colectiva de sus intereses frente a las políticas de gobierno en marcha y otra que intentaba dar respuesta a las necesidades apremiantes de provisión de bienes públicos (carreteras, acceso a agua, distritos de riego, control de plagas, entre otros) que impulsaron la modernización del sector.

El estímulo directo se estableció desde el gobierno de Alfonso López Pumarejo (1934-1938) y su política agraria reformista, el cual fue asumido por los sectores de grandes propietarios rurales como una amenaza al régimen tradicional de tenencia de la tierra y que sin duda, incidía en la

\footnotetext{
${ }^{3} \mathrm{El} \mathrm{lector}$ interesado en conocer con más detalle la historia de la SAC y tener una visión general de la evolución y las organizaciones gremiales del sector agropecuario puede remitirse al trabajo de Bejarano (1985) y de Machado y Samacá (2000). En cuanto a la historia de las organizaciones gremiales en Colombia, los trabajos de Junguito (2019) y Losada (2000) ofrecen una visión general de las organizaciones gremiales en diferentes sectores del país y del contexto normativo en el que se desarrollaron.

${ }^{4}$ En 1928 se constituyó el Comité Departamental de Cafeteros, pero como su nombre lo indica, este solo reunía a agricultores dedicados a un cultivo específico (Sáenz, 1992, p. 260).
} 
exacerbación del malestar rural que se presentaba desde tiempo atrás en distintas regiones del país, dada la expectativa de redistribución de la tierra (Bejarano, 1985, pp. 187-190). Esto es un indicativo de que la Sociedad, como cuerpo que agremiaba a dichos propietarios en este espacio regional, se constituyó en 1937, es decir, a pocos meses de la expedición de la Ley 200 de 1936 que pretendía establecer la función social de la propiedad (Palacios, 2011) y clarificar los derechos de propiedad sobre las tierras, fueran o no explotadas (Bejarano, 1985, pp. 199-200).

Sin embargo, como ya se mencionó, la Sociedad se instituyó como un instrumento que buscaba no solo acceso a las instancias políticas de decisión sino también la obtención de recursos para sus asociados. En la Sociedad existía, además, una preocupación sobre la modernización de la agricultura y la situaba en el mismo plano de iniciativas institucionales como la apertura de la Estación Experimental Agrícola de Palmira en 1928 y la Misión Chardon en 1929, ambas agenciadas por Ciro Molina Garcés y Carlos Durán Castro (Mejía, 2003).

Entre las diferentes problemáticas relacionadas con bienes públicos destacó el tema de la seguridad (como era llamado en la época) o protección de los derechos de propiedad liberales (en el lenguaje neoinstitucional). Esta preocupación, relacionada con el malestar en los campos, fue otro de los argumentos poderosos que impulsó a los hacendados a agremiarse. El malestar rural, como fenómeno sociopolítico, tuvo diversas y complejas raíces y manifestaciones con distintos matices según la zona del país que se quiera examinar. Sin embargo, desde el punto de vista de los terratenientes, el abigeato y la proliferación de bandas de asaltantes constituían un problema estrictamente de seguridad que debía ser enfrentado haciendo uso de los mecanismos que la asociación facilitaba. En 1945 el presidente de la Sociedad, Luis Felipe Rosales, y su homólogo del Comité Ganadero del Valle, Hernando Caicedo, en mensaje dirigido al presidente de la República, Alberto Lleras, señalan:

Está a la vista la inseguridad que reina actualmente en los campos y la falta de garantías efectivas especialmente para el gremio de pequeños cultivadores, expuestos constantemente a los ataques de cuatreros y maleantes. Los agricultores han soportado toda clase de perjuicios: el hurto, el robo y el atraco, sin que hasta la fecha hayan logrado el amparo a que tienen derecho como creadores de riqueza y como ciudadanos colombianos (sAG, julio-agosto, 1945, p. 29).

En esta misma misiva expresan tener confianza en que Lleras "tomará las medidas del caso para que cesen tantos males: abandono de los campos, escasez de víveres, corrupción del pueblo campesino, carestía de la vida" (sAG, julio-agosto, 1945, p. 29). Tiempo después, en 1947 la Sociedad solicitó al presidente Mariano Ospina Pérez el establecimiento del Cuerpo de Policía Rural 5 y posteriormente, adelantó gestiones ante las autoridades departamentales para intensificar las campañas sobre protección rural ${ }^{6}$ solicitudes y gestiones que vemos repetirse constantement $\AA^{7}$ y en ocasiones de manera coordinada con el Comité de Ganaderos departamental 8 En los informes de 1951 y 1952 se encuentran menciones de la manera en que actuaba la Sociedad ante sus afiliados.9 A propósito de las necesidades de protección policiva en determinadas zonas rurales:

${ }^{5}$ SAG, julio-octubre, 1947, pp. 13-14.

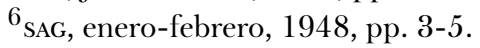

${ }^{7}$ SAG, diciembre, 1949 , pp. 2-5.

${ }^{8}$ SAG, diciembre, 1950 , pp. 18-20.

${ }^{9}$ SAG, enero, 1952 , pp. 5-6. 
Cuando quiera que los campesinos han acudido a nuestras oficinas en solicitud de su intervención ante las autoridades, hemos tenido la satisfacción de haberlos ayudado eficazmente, porque los órganos del poder público no se han mostrado indiferentes a nuestros reclamos y antes bien los han atendido con diligencia (sAG, diciembre, 1952, p. 2).

Aunque en las décadas siguientes el tema de la seguridad perderá cierta relevancia al disminuir la frecuencia en que se menciona en los informes y artículos de la Revista, en la década de los ochenta volverá a constituirse en un tema de preocupación constante en las discusiones de la junta directiva de la asociación.

\section{La lógica de los servicios}

Aunque la necesidad de materializar una identidad de intereses económicos -por medio de la creación del gremio- es central en los primeros años de vida de la SAG, es importante dar cuenta de otras actividades que ocupaban buena parte de sus esfuerzos y que en conjunto, constituían otro de sus ejes en el propósito de apoyar y promover el sector agropecuario.

Estas actividades apuntaban a resolver las necesidades o problemas, desde el punto de vista de sus asociados, relacionados con la provisión de bienes públicos al sector. Dichas actividades se dividen en dos grandes acciones: de gestión y/o coordinación interorganizacional; y de difusión de conocimientos y apoyo técnico.

Las actividades de gestión y/o coordinación interorganizacional consistían en las intermediaciones que la Sociedad hacía entre los hacendados y/o ganaderos, así como los diversos organismos estatales tanto del legislativo (concejos, asambleas, cámara de representantes y senado), como del ejecutivo (secretarías departamentales, ministerios u organismos descentralizados, pero también alcaldes, gobernadores o presidente de la República). Actividades destinadas a: 1) Obtener, ampliar, agilizar y/o ejecutar recursos para la construcción o reparación de caminos, carreteras y puentes, y obras de control de inundaciones; 2) Mejorar las condiciones de comercialización de los productos del campo a través de la regulación de los controles y defensa de precios (de maíz, arroz, fríjol, entre otros), la vigilancia sobre las importaciones de alimentos que pudieran afectar dichos precios y la presión sobre la administración de los Ferrocarriles Nacionales para bajar los costos de transporte o facilitar la movilización de animales, insumos y cosechas; 3) Aumentar o renegociar créditos agropecuarios, gestionar condiciones favorables para cultivadores de un producto específico (cacao, maíz, etc.), solicitar el incremento de capital de entidades ya existentes -como la Caja de Crédito Agrario y Minero y el Banco Agrícola Hipotecario- o promover la creación de nuevas como el Banco Ganadero; 4) Reducir costos de producción, presionando la baja de precios de insumos; 5) Superar las dificultades de importación de maquinaria agrícola inherentes al restrictivo régimen de importaciones del modelo económico (buscando el aumento de los llamados cupos de importación). De particular sensibilidad es la adquisición de equipos especiales para la perforación de pozos artesianos; 6) Reducir la carga tributaria sobre el sector (impuestos de renta, al patrimonio, catastral y parafiscales).

La Sociedad también gestionó ante entidades privadas y otros actores no estatales la obtención de beneficios que, de manera aislada o individual, seguramente habrían sido muy difíciles de lograr. Así, cuando se presentó una situación de escasez de gasolina en 1947 que amenazó con paralizar la maquinaria agrícola, la Sociedad se dirigió al gerente de la Tropical Oil Company solicitando 
prelación en las ventas de combustible a los agricultores, cuyo funcionario accedió a la solicitud:10 o en 1948 cuando el gremio de agricultores intercedió entre productores y la industria procesadora del cacao para encontrar salida a un conflicto originado por los precios de compra de la cosecha 11

Por su parte, las actividades de difusión de conocimientos y apoyo técnico se focalizaban en la necesidad de proveer recursos, habilidades y asistencia técnica, agronómica y legal a los agricultores valiéndose de los instrumentos y mecanismos de acercamiento de la Sociedad, los cuales consistían en: reparto gratuito de semillas (pastos, tabaco, hortalizas, etc.); asistencia en el desarrollo de campañas diversas (exterminio de la hormiga arriera, instalación y conservación de bañaderas de ganado, distribución de cupos de alambres de púas, entre otros); realización de conferencias, charlas y seminarios sobre algún producto o tema específico (irrigación, electrificación, cooperativismo, agremiación, seguridad rural, etc.); elaboración y entrega gratuita de boletines, folletos y revistas informativas e instructivas sobre cultivos u otros temas agropecuarios (caña, cacao, yuca, hortalizas, avicultura, porcicultura, etc.). Al respecto, hay que anotar que la propia Revista Agrícola y Ganadera publicó ampliamente todo tipo de notas relativas a asuntos agronómicos y pecuarios.

A propósito de estas actividades y servicios, es importante notar cómo su misión se identifica con la primera Sociedad de Agricultores de Colombia fundada en 1871, la cual posiciona a la difusión técnica y tecnológica como fundamento del progreso material (Bejarano, 1985, pp. 110111). Esto se hace patente en los informes publicados en la Revista cuando al dar relación de estas labores se apunta su relevancia, como lo hace el presidente de la Sociedad, Luis Felipe Rosales, en su informe de 1948:

La Corporación considera que la divulgación de métodos eficaces para el laboreo de la tierra e incremento de la agricultura en sus diferentes órdenes beneficia notablemente a las personas vinculadas al campo y creadoras de riqueza. En esta forma, además de conservar contacto permanente con los agricultores, se realiza una labor cultural de magníficos resultados (sAG, noviembre, 1948, p. 6).

En conjunto a los anteriores servicios, la Sociedad suministraba a sus afiliados estadísticas y datos de agricultura y ganadería como: precios promedio de productos agropecuarios, costos de sueldos y jornales, valores promedio de tierras, entre otros datos relevantes sobre la dinámica del sector. Expedía certificados en los que se acreditaba el carácter de propietario agrícola del solicitante, los cuales servían para adelantar trámites de solicitudes de créditos, importación de maquinaria y vehículos, repuestos e insumos (combustibles, lubricantes, etc.). Ayudaba a registrar o tramitar salvoconductos de armas con destino a la defensa de las haciendas. Asistía en la consecución de cotizaciones de maquinaria e implementos agrícolas. E incluso, ofreció servicios de resolución de conflictos entre los asociados como "(...) inspecciones oculares para zanjar diferencias entre agricultores asociados, dentro del acostumbrado ambiente de imparcialidad de una entidad de esta naturaleza" (sAG, diciembre, 1952, p. 5).

\section{Funcionamiento de la Sociedad}

Toda esta serie de acciones requerían de la SAG una gran capacidad de coordinación y relaciones a diferentes niveles, desde lo técnico hasta lo político, y desde lo local a lo nacional. Esto llevó a la SAG a desarrollar una estrategia de relaciones mediante participación y entrecruce de juntas directivas de diferentes organizaciones e instituciones que le permitieran influir en la toma de decisiones y

${ }^{10}$ SAG, julio-octubre, 1947, pp. 13-14.

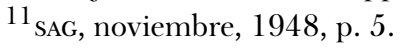


acceder a recursos e información. Así, desde muy temprano, entre las principales actividades de la agremiación estuvo la promoción de la creación de nuevos cuerpos o asociaciones sectoriales a nivel local y regional, así como la búsqueda de la representación de la Sociedad en estos y en juntas y mesas directivas de entidades públicas existentes que le permitieran construir y desarrollar toda una red de alianzas y colaboraciones que aumentaran su efectividad en el logro de su misión.

Por ejemplo, en 1940 la Gobernación del Valle decretó la creación de Cámaras de Agricultura municipales (para Buga, Palmira, Cartago, Roldanillo y Sevilla) y le otorgó a la Sociedad el derecho a designar a uno de sus cinco miembros en cada una de ellas. Algunas de las funciones de estas cámaras eran: asegurar partidas de los presupuestos municipales para la construcción de caminos de penetración, promover campañas contra las plagas que atacaban los cultivos, la difusión de conocimientos relacionados con el agro, y actuar como juntas asesoras de la Secretaría de Agricultura y Fomento ${ }^{12}$ En 1943 la Sociedad respondió a la solicitud de la Asociación Colombiana de Ganaderos para crear un comité ganadero departamental y designó a dos miembros representantes para la junta de dicho comité ${ }^{13}$ Tres años después, el presidente de la Sociedad, Alberto Abondano Herrera, en su informe de labores del año 1946, habló de la reciente instalación de Juntas Municipales de Fomento Agrícola, con una nueva denominación, en ocho poblaciones conforme disposiciones de la SAC y en cooperación con la Caja de Crédito Agrario:

Funcionan en la actualidad Sociedades de Agricultores Municipales en Palmira, Buga, Tuluá, Roldanillo, Bolívar, Toro, Versalles y La Unión, y se proyecta la instalación de otras en varios municipios. (...) Creemos oportuno continuar con la labor de instalación de nuevas Sociedades de Agricultores Municipales, hasta conseguir el funcionamiento de ellas en todos los municipios del Valle, lo que representaría para nosotros una mejor coordinación de nuestros programas, a la vez que una efectiva fuerza de unión en uno de los departamentos agrícolas más productores del país (sAG, enerofebrero, 1947, pp. 12-14, 32-33).

Con frecuencia, los informes anuales dan cuenta de la elección de representantes de la Sociedad de Agricultores del Valle en distintas corporaciones del nivel departamental tales como: Junta Departamental de Caminos, Junta de Control de Precios ${ }^{14}$ Tribunal Seccional del Trabajo ${ }^{15}$ Junta Departamental de Vivienda Popular ${ }^{16}$ Juntas de Catastro Municipales en las que tendrían asiento las Sociedades de Agricultores municipales 17 y la junta directiva del Hospital Departamental 18 Asimismo, en el orden nacional tenía representantes en: la junta directiva del Instituto Nacional de Abastecimientos INA 19 la misma Sociedad de Agricultores de Colombia -la cual, a su vez, tenía un representante en la Sociedad de Agricultores del Valle- ${ }^{20}$ la junta directiva del Banco de la República $\sqrt{21}$ y el Consejo Administrativo de los Ferrocarriles Nacionales ${ }^{22}$ Para algunas de

$12_{\text {SAG, septiembre, 1940, pp. 23-24. }}$

${ }^{13}$ SAG, diciembre, 1943 , p. 10.

${ }^{14}$ SAG, enero-febrero, 1947 , pp. 12-14, 32-33.

${ }^{15}$ SAG, julio-octubre, 1947 , pp. 13-14.

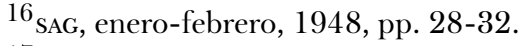

${ }^{17}$ SAG, enero, 1956 , p. 6.

$18_{\text {SAG, enero, } 1956 \text {, p. } 6 .}$

${ }^{19}$ SAG, enero-febrero, 1948, pp. 3-5; diciembre, 1949, pp. 2-5; enero, 1952, p. 6.

${ }^{20}{ }_{\text {SAG, diciembre, } 1949 \text {, pp. } 2-5 .}$

${ }^{21}$ SAG, enero-febrero, 1948, pp. 3-5; diciembre, 1949, pp. 2-5; enero, 1952, p. 6.

${ }^{22}$ SAG, enero, 1952 , p. 6. 
estas entidades, la representación debía ser compartida entre varias asociaciones como: Asociación Nacional de Industriales ANDI, Cámara de Comercio, Federación Nacional de Comerciantes FENALCO, así como la banca u otras Sociedades de Agricultores regionales.

La participación de la Sociedad en estos espacios decisorios, como estrategia de influencia sobre diversos asuntos que afectaban al sector agropecuario, parece haberse sostenido con regularidad a lo largo del periodo estudiadd 23 . Así, en 1962 encontramos, según informe rendido por el presidente de la Sociedad, Alfonso Jaramillo Arango, a la Asamblea General de afiliados, que la Sociedad tenía asiento en al menos once juntas o comités:

(... ) se nombraron oportunamente, mediante el sistema de votación y trámites de rigor, los representantes de esta entidad en las Juntas Directivas de la Sociedad de Agricultores de Colombia SAC; Banco de la República; Hospital Departamental Universitario; Corporación Autónoma Regional del Cauca CVC; Consejo Seccional del Instituto Colombiano de la Reforma Social Agraria Incora; Junta Directiva Seccional de la División Pacífico; Comité Departamental de Caminos Vecinales; Servicio Nacional de Aprendizaje sena; Conciliatura de la Facultad de Agronomía; Junta Departamental de Salario Mínimo; Caja de Crédito Agrario Industrial y Minero; etc. (saG, enero-febrero, 1963, pp. 7-16).

\section{Dificultades de la Sociedad}

A pesar de la efectividad de esta estrategia de participación en juntas directivas, la Sociedad enfrentó dificultades relacionadas con agrupar la diversidad de intereses que se encontraban en el sector agrícola y ganadero vallecaucano. Por ejemplo, los llamados a promover y fortalecer la agremiación son persistentes a lo largo de estos años. En 1945 Guillermo Ramírez Romero lamentó la desunión entre los agricultores y la apatía a la hora de emprender acciones de interés conjunto, así como la falta de articulación con el Gobierno y las instancias institucionales 24 . Poco después, el entonces presidente, Benjamín Isaza, en su último informe de 1947 reprochó que “(...) el principal gremio de la patria es seguramente el menos organizado, y la experiencia nos ha enseñado que en la hora en que vivimos poco o nada se consigue sin cerrar filas y demandar constantemente de los altos poderes, las medidas que han de constituir su redención” (sAG, enero-febrero, 1948, pp. 3-5).

A la costumbre de los hacendados de rehuir el establecimiento de coaliciones formales se agregaba la creciente presencia en Cali -a partir de la segunda mitad de la década de 1940- de nuevas asociaciones sectoriales que buscaban incidir también en la estructura de decisiones del Estado, lo cual se ve reflejado en la Revista Agrícola y Ganadera en una doble actitud tanto de queja por la debilidad del gremio, como de continua convocatoria a unir fuerzas alrededor del mismo:

Si los agricultores correspondieran a las invitaciones que frecuentemente les hace esta Sociedad para que se agremien alrededor suyo, a fin de luchar unidos y librar toda clase de campañas sobre incremento agrícola y pecuario, sería muy distintos los recursos de

\footnotetext{
${ }^{23}$ Bejarano (1985, pp. 215-216) sostiene que desde los años cuarenta los gremios operaban dentro de un sistema de relaciones entre el Estado y los organismos corporativos a través de la representación gremial en consejos o cuerpos directivos del Estado, en los mecanismos de regulación de la vida económica y en las formas de representación estatal en las directivas de las corporaciones gremiales.

${ }^{24}$ Por una Sociedad Nacional de Agricultores, SAG, noviembre-diciembre, 1945, pp. 4-1.
} 
que podríamos disponer hoy día y muy superiores los resultados que obtendríamos en favor de estas industrias que carecen de muchos medios de progreso, culpa a nuestra propia indiferencia (saG, enero-febrero, 1948, pp. 3-5).

Aunque es difícil determinar en qué medida la existencia de organizaciones como fenalco, Cámara de Comercio de Cali, Compañía Distribuidora de Azúcares, Asociación de Productores de Caña ASOCAÑa o la ANDI, debilitaron o ralentizaron el fortalecimiento y capacidad de influencia de la SAG, es claro que la fragmentación en la representación gremial era un hecho no solo en el mundo de los negocios vallecaucano ${ }^{25}$ sino nacional. Un mismo empresario podía pertenecer e incluso presidir dos o más asociaciones, o varios miembros de una familia podían dividirse la participación en diferentes asociaciones. Por ejemplo, Hernando Caicedo integraba las juntas directivas de la SAG y del Comité Ganadero del Valle, también fue socio fundador de la Distribuidora de Azúcares y prominente directivo de la seccional de la ANDi y la Cámara de Comercio de Cali. Eugenio Castro Borrero y Harold Eder Caicedo pertenecieron a las juntas directivas de la SAG y de la ANDI (Eder se afiliaría más tarde a la Distribuidora de Azucares y a la ANDI). Juan E. Ulloa Caicedo se integró a la junta de la Sociedad de Agricultores de Palmira y de la ANDI (sus hermanos, Óscar y Camilo, pertenecían a la SAG). José Castro Borrero (hermano de Eugenio), alcalde de Cali en 1948, llegaría a presidir la seccional de la ANDI en esta ciudad en la década de 1950. Carlos Sardi Garcés, miembro de la seccional ANDI, fue también alcalde en 1949 y presidió la junta directiva de la seccional de FENALCO (sus hermanos Eduardo, Jaime, Luis Emilio y Mario pertenecieron en distintos periodos a la SAG).

De esta manera, se presentó un intrincado entrecruzamiento de asientos y cargos en los que, obteniendo preeminencia de los intereses que representaba la ANDI, los lazos de parentesco permitían a un sujeto o grupo familiar atender sus intereses en otros sectores. Se precisará de un estudio posterior que nos permita analizar las causas por las cuales uno u otro de estos individuos o grupos decidieron concentrar y/o diversificar sus acciones de influencia en uno u otro gremio.

La Sociedad, por su parte, demandaba de sus afiliados esfuerzos para ocupar mayores espacios de representación directa en la política, en "Congreso, Asambleas y Concejos Municipales, pues el agro representa la principal fuerza viva de la nacionalidad y mal puede continuar sin voceros en los cuerpos colegiados del país" (sAG, enero-febrero, 1948, p. 32); y llamó a incrementar las afiliaciones de nuevos asociados 26 Para finales de los años cincuenta, la creciente insatisfacción entre hacendados y ganaderos por las medidas estructurales propuestas por el plan Lilienthal (coyuntura que describiremos más adelante) volverá urgentes los esfuerzos de agremiación como estrategia de defensa de sus intereses. En un editorial, Alfonso Jaramillo Arango declaró:

Por la evolución misma del país en los últimos años, hemos desembocado en una especie de corporativismo no declarado. El Gobierno y el Parlamento no dan atención efectiva sino a las grandes asociaciones, a las fuerzas sindicales organizadas. Por este motivo la voz apacible y las manifestaciones tímidas de los gremios de Agricultores y Ganaderos, se escuchan sin entusiasmo y nunca se buscan sus consejos (Agremiación, SAG, mayo-junio, 1959, pp. 5-6).

\footnotetext{
${ }^{25}$ Hasta la fecha, los estudios sobre asociaciones gremiales en el contexto del Valle del Cauca son escasos. Recientemente han aparecido análisis como el de Batero (2018) sobre la Asociación de Fabricantes y Productores, y el realizado por Londoño (2018) sobre la Cámara de Comercio de Cali.

${ }^{26}{ }_{\mathrm{SAG}}$, diciembre, 1952 , p. 5.
} 
En este mismo editorial, Jaramillo Arango reprochó que se consulte a FENALCO y a la ANDI -abriendo con ellas amplias e intensas negociaciones- cada vez que se emprende una reforma tributaria o se busca modificar un arancel de las aduanas, mientras que "El País se ve privado de la experiencia de quienes manejan las cosas del campo, conocen sus adversidades, afrontan la lucha agria con la naturaleza y tienen el derecho democrático de discutir e intervenir con sus opiniones" (Agremiación, SAG, mayo-junio, 1959, pp. 5-6) cuando se trata de reformar o promulgar leyes agrarias.

En el informe rendido por Luis Bernardo Salcedo Cifuentes a la Asamblea General de la Sociedad, se apunta a las causas de la debilidad de la entidad:

El número de socios, no obstante haber subido de 246 a fines de 1958, a 360, en la actualidad, da una idea clara de la falta de entusiasmo que deberían tener los agricultores del Valle por fortalecer numérica y económicamente a la institución encargada de llevar su vocería y de asumir la defensa de sus intereses. (... nuestras campañas se quedan a mitad de camino y carecen de la intensidad que debieran tener, porque los medios para adelantarlas están fuera del alcance de nuestros recursos y porque las personas encargadas de llevarlas a buen término no siempre pueden disponer del tiempo que ellas requieren (SAG, mayo-junio, 1959, pp. 5-6).

\section{La Sociedad de Agricultores del Valle frente a la Misión Currie, el Plan Lilienthal y la Reforma Agraria}

En el curso de los 25 años que abarca el material consultado de la Revista Agrícola y Ganadera, la Sociedad de Agricultores del Valle (misma que a partir de 1963 se fusionó con el Comité de Ganaderos y la Sociedad de Agricultores para formar la SAG) desempeñó un papel activo en defensa de los intereses de sus asociados durante tres coyunturas originadas en iniciativas gubernamentales que buscaban modernizar el campo a través de la modificación de la institucionalidad agropecuaria. En estas acciones se evidenció de manera clara no solo la estrategia de relaciones y capacidad de coordinación de la Sociedad, sino también el alcance y la efectividad de su lógica de la influencia.

La primera de estas coyunturas es la implementación de las recomendaciones de la misión del Banco Mundial presentadas en 1950 por Lauchlin B. Currie; la segunda, es la aplicación del programa de inversiones para el valle geográfico del río Cauca propuesto por David Lilienthal en 1954; y por último, la discusión, sanción e implementación de la Ley 135 de 1961 o Reforma Agraria.

\section{La oposición a la Misión Currie}

La Misión Currie se inscribía en las políticas de asistencia y promoción del desarrollo en América Latina, adelantadas por los Estados Unidos después de la Segunda Guerra Mundial, sobre la implementación de una serie de instrumentos económicos y políticos tendientes a atacar los problemas estructurales del país (López, 1995). El documento entregado por la Misión al presidente Mariano Ospina Pérez resaltó la baja productividad rural de las tierras más fértiles ubicadas en las zonas planas a causa de su dedicación casi exclusiva a la ganadería extensiva, y formuló que "el método más efectivo de alcanzar la máxima utilización de la tierra es un sistema de tributación que grave el uso inadecuado de la misma” (sAG, mayo, 1951, p. 2). 
En una carta enviada en enero de 1951 al presidente del Comité de Desarrollo Económico del Plan Currie, Alfredo García Cadena, el presidente de la Sociedad de Agricultores de Colombia, Carlos Echeverri Cortés, hace una propuesta sobre el impuesto predial en el informe de la Misión:

(...) que la tarifa básica del impuesto predial se aumente progresivamente a medida que la renta neta recibida de la tierra descienda por debajo de un determinado porcentaje de utilidad con relación al valor corriente de la tierra en el mercado, según lo determine el Instituto Geográfico, y al efecto conceptúa que las tierras adecuadamente labradas en las planicies de Cundinamarca deberían producir una utilidad por lo menos del $10 \%$ en relación con el precio del mercado. Para las tierras situadas en los valles, la proporción normal del rendimiento podría fijarse en un $14 \%$ del valor en el mercado y las tarifas aumentarían en la forma correspondiente. [Pues según el argumento de Echeverri Cortés] La Sociedad de Agricultores de Colombia, considera que las anteriores recomendaciones de la Misión Currie, tal como se hallan expuestas en el informe a que me refiero, entrañan un gravísimo peligro para la estabilidad y desarrollo de la industria agropecuaria. De ahí que, en su condición de cuerpo consultivo del Gobierno, de representante auténtico de los agricultores y ganaderos colombianos y de vocero de todos los hombres del campo que patrióticamente y venciendo innumerables dificultades laboran pacientemente una efectiva riqueza para Colombia, se permita, por mi conducto, hacer llegar al Comité de Desarrollo Económico del Plan Currie, sus observaciones (...) así como las razones en que se funda para considerar impracticables las recomendaciones en él contenidas (sAG, mayo, 1951, p. 2).

Tales observaciones se refieren a la inexistencia en el país de un sólido crédito agropecuario, así como las dificultades para acceder a los avances técnicos e insumos como fertilizantes y plaguicidas, la imprevisibilidad del clima, la inseguridad rural, los problemas de transporte y almacenamiento, la falta de irrigación, e incluso a los intereses políticos; todo lo cual impide, en la visión de la Sociedad, que la productividad agrícola crezca de manera estable y conforme las nuevas aspiraciones del gobierno central.

En febrero del mismo año, el presidente de la Sociedad de Agricultores del Valle, Ernesto González Piedrahita -destacado ganadero de la región-, manifestó su adhesión a las opiniones que Echeverri Cortés expuso en su carta, aduciendo más o menos los mismos argumentos que este sostuvo para oponerse y rechazar el incremento progresivo al impuesto predial formulado por el informe del Banco Mundial: la ausencia de un completo plan de irrigación de tierras, las dificultades de acceso al crédito, la impracticabilidad de la agricultura en extensas tierras anegadizas que serían también gravadas, la falta de caminos aptos, y la agobiante presión que otros impuestos ejercían sobre los hacendados (catastro, impuesto de patrimonio, policía rural, caminos, entre otros). González Piedrahita mencionó:

Para conducir a los terratenientes vallecaucanos a abandonar el pastoreo por medios coercitivos, como multas, confiscaciones o desmedidos impuestos, se necesitaría que el Estado pudiera ofrecerles un vasto, completo y eficiente plan de irrigación en sus tierras labrantías. Para nadie es dudoso que la agricultura en el trópico, contando solamente con el agua que cae del cielo, con tanta eventualidad, no puede ser un negocio, una empresa seria y segura. De tres cosechas se pierden dos y se aprovecha una (...) En esas condiciones la agricultura en grande escala no es una explotación económica sino una aventura. [Sobre las tierras inundables en los márgenes de los ríos del Valle, señala que]... la carga impositiva se empeñaría en modificar la naturaleza y crearía una situación de aberrante injusticia para con los dueños de esas vegas anegadizas, al tratar de convertirlos por medios compulsivos, de pastores, como lo indica la naturaleza, en agricultores, como lo quiere el plan Currie (sAG, febrero, 1951, p. 3). 
La defensa de la institucionalidad vigente en materia de la propiedad rural hecha por González Piedrahíta apela a diferentes tipos de justificaciones, incluso de índole científica, para sustentar la inconveniencia de desplazar el ganado bovino de las zonas planas a las montañosas:

El ramal occidental de la cordillera en este departamento es de tierra muy pobre en calcio y fósforo y por eso las razas vacunas decaen de una generación a otra. Además, las plagas de garrapata y nuche por su inmensa proliferación impiden que allí prospere la industria pecuaria. En cuanto a la cordillera central, de mejores tierras que la occidental, tiene la desventaja de ser excesivamente abrupta, lo que causa la destrucción de los pastos por la erosión y el tránsito de los animales (...) Además esas tierras no tienen vías de acceso (saG, febrero, 1951, pp. 3-4).

En vista de que el Comité de Desarrollo Económico del Plan Currie inició el trámite legislativo para la aprobación del impuesto, haciendo caso omiso de las quejas y recomendaciones de la SAC, esta última se dirigió a González Piedrahita solicitándole que de manera urgente reúna a la junta directiva de la Sociedad de Agricultores del Valle para que "estudie detenidamente este problema y se dirijan al señor Presidente de la República y a los señores ministros de Agricultura y Hacienda, presentándoles sus puntos de vista sobre el particular" (sAG, mayo, 1951, p. 4). Prueba de que la Sociedad de Agricultores del Valle no subestimó la gravedad de la situación fue el telegrama dirigido al gobierno central con el que respondió a esta invitación de la SAC, suscrito por 73 propietarios de la región. En el telegrama, la Sociedad reiteró los factores adversos que, según su criterio, entorpecen el crecimiento de la productividad en el campo, así como la "escasez y carestía de maquinaria e implementos agrícolas" y las elevadas pérdidas recientes a causa de un prolongado invierno seguido de una epidemia de aftosa. Concluye dicha comunicación pidiendo al gobierno central que se abstenga de aprobar los impuestos progresivos, "punitivos y confiscatorios" propuestos por el Plan Currie, que no harían sino complicar aún más la situación de los hombres del campo y desestimular la producción de carne y leche 27

La prensa local fue también un medio en esta campaña a favor de "la agricultura y la ganadería del país": el diario Relator lo hace "desde sus columnas editoriales con irrebatibles argumentos"; y el Diario del Pacífico por medio de "la publicación de diferentes materiales en favor de los intereses agrícolas y ganaderos de la nación”. Ambos reciben reconocimiento público y sincero agradecimiento de la junta directiva de la Sociedad ${ }^{28}$ Este despliegue publicitario para hacer de la causa de los terratenientes una causa regional y nacional merecería un análisis aparte en el que tendríamos que considerar el entrecruzamiento de intereses de los empresarios y la consecuente injerencia de algunos terratenientes miembros de la Sociedad sobre la orientación editorial de estos diarios 29

La iniciativa legislativa del Comité de Desarrollo Económico del Plan Currie es finalmente "derrotada" en agosto de 1951, pues según Carlos Echeverri Cortés, presidente de la SAC, fue “merced a la brillante labor desplegada por estas instituciones agrícolas [las Sociedades de Agri-

${ }^{27}$ SAG, mayo, 1951 , pp. 5-6.

${ }^{28}$ SAG, mayo, 1951, pp. 27-28.

${ }^{29}$ Encontramos, por ejemplo, que la familia Eder y Hernando Caicedo, terratenientes, ganaderos e industriales, miembros de la Sociedad de Agricultores del Valle (Harold Eder es miembro principal de su junta directiva entre 1949 y 1952) eran accionistas del Diario del Pacífico. Collins (1981) y Sáenz (1992) ofrecen una interesante discusión sobre la relación entre el poder económico (industrial), prensa e ideología a mediados del siglo xx en Colombia, en la que pone en evidencia las estrategias de campaña ideológica desplegadas por la ANDI en la prensa capitalina y de las principales ciudades. El examen y comparación de este análisis con la campaña en contra de la iniciativa de la Misión Currie se hacen aún más pertinentes si tenemos en cuenta que la seccional de la ANDI en Cali y la Sociedad de Agricultores del Valle compartían afiliados, y que también la ANDI publicó anuncios y participó en la redacción de contenidos editoriales y de opinión en Relator y Diario del Pacífico en 1950. 
cultores del país]" (saG, enero, 1952, p. 4). El gobierno nacional, dice González Piedrahíta, "tuvo muy en cuenta sus documentadas exposiciones y la justicia que asistía a estas entidades para llevar adelante su tenaz campaña” (sAG, enero, 1952, p. 4). Se trata para la Sociedad de un triunfo significativo para los gremios de agricultores y ganaderos, y de manera específica, para el del Valle del Cauca.

\section{La oposición al Plan Lilienthal}

El Plan Lilienthal fue un ambicioso proyecto inspirado y concebido a semejanza del ejecutado en el valle del río Tennessee en Estados Unidos en 1934 (Ekbladh, 2002). Este plan proponía realizar grandes inversiones en construcción de puertos, electrificación, tecnificación agropecuaria, irrigación y desecación, servicios públicos e investigación para la promoción de la industria en la hoya del alto Cauca. En lo agrícola, apuntaba a convertir la zona plana "en una tierra perfectamente irrigada, desecada y dedicada a cultivos intensivos de productos de alto rendimiento y alto precio en el mercado [internacional]" (Plan Lilienthal, 1954, p. 4), por lo que recomendó desplazar la ganadería a la cordillera 30 Uno de los proyectos más importantes para lograr estos objetivos era el de regular el curso del río Cauca por medio de la construcción de embalses que, al servir para el establecimiento de centrales hidroeléctricas, permitirían ampliar la infraestructura energética. El plan establecía su financiación a través de la contribución pública y privada en la siguiente proporción: $56 \%$ inversión de particulares, $16 \%$ prestamos, $11 \%$ institutos, $6 \%$ departamento, $5 \%$ nación, $3 \%$ municipio y $3 \%$ valorización 31

Inicialmente, la Sociedad de Agricultores del Valle se mostró "animada del mejor espíritu de cooperación dentro de la órbita de sus actividades”, pues como González Piedrahita afirmó:

Para la Sociedad de Agricultores del Valle han sido tanto más interesantes los programas que constituyen el Plan Lilienthal, cuanto que dentro de él cae de lleno la solución de los problemas que han constituido su permanente inquietud, tales como las frecuentes inundaciones del río Cauca, la práctica desaparición de los caminos en épocas de lluvia, la continua invasión de valiosísimas zonas de terrenos con lagunas fácilmente desecables, entre otros (sAG, diciembre, 1954, p. 6).

Sin embargo, dos años después, la financiación y actividades de la entidad ejecutiva encargada de adelantar el plan, que emuló a su homóloga norteamericana, la Tennessee Valley Authority, comenzó a causar malestar entre los propietarios rurales. En efecto, la Corporación Autónoma Regional del Cauca (CVC) funcionaría con recursos obtenidos del cobro de un impuesto del 4x1 000 sobre el costo del catastro, gravamen a opinión de la Sociedad, oneroso:

(...) habida consideración a las exacciones ya vigentes y a la tendencia de las juntas de hacienda que funcionan en los municipios, de elevar año por año el avalúo catastral de las tierras rústicas y de los predios urbanos (...) Ahora, con el 4x1 000 adicional para la CVC este impuesto se eleva en un ciento por ciento. [Todas estas cargas] crearán irremediablemente un estado insoportable de angustia económica entre el gremio de propietarios, y llegará el momento en que a pesar de la buena voluntad, desprendimiento patriótico y espíritu de resignación, no podrá sobrellevarlo (sAG, diciembre, 1956, p. 11).

${ }^{30}$ Plan Lilienthal, 1954, p. 34.

${ }^{31}$ Plan Lilienthal, 1954, p. 69. 
La Sociedad fue escéptica ante la ejecución de sus proyectos "por hallar desproporción entre la magnitud de ellos y la disponibilidad de recursos financieros dentro de las aflictivas circunstancias económicas nacionales hoy predominantes" (sAG, diciembre, 1956, pp. 11-12) y manifestó su preferencia por una destinación más focalizada de dichos recursos en obras de canalización y desecación:

Siempre hemos pensado que las actividades de la Corporación Autónoma Regional del Cauca debieron en su parte inicial, a intento, entre otros fines, de adquirir popularidad e infundir fe entre los contribuyentes, adelantar obras en un plan modesto para la rehabilitación de las tierras y su mejor explotación, vertebrado todo esto a los programas ${ }^{32}$ [Y concluye] Nosotros no hemos escatimado declaraciones sobre el aspecto seductor del Plan Lilienthal, pero por más que sus proyectos representen una promesa de redención para esta comarca, hemos tenido el valor de hacerles ver a los Órganos del Estado que en un dado momento dicho Plan puede erigirse en instrumento de exterminio de un gremio respetable dentro del país, puesto que sólo gravita sobre los terratenientes dejando sin gravamen a muchos sectores de la economía que irían a recibir los mismos beneficios. Esto en la hipótesis de que los recursos financieros de la Nación hagan viables los planes de la Corporación Autónoma, y el 4x1 000 no se destine exclusivamente al sostenimiento de una costosa fronda burocrática. Ha sido éste el pensamiento tranquilo y leal de la Sociedad de Agricultores (SAG, diciembre, 1956, pp. 11-12).

En abril de 1957, a pocas semanas del retiro del poder del general Gustavo Rojas Pinilla (al que se le atribuye gran parte del impulso al Plan Lilienthal), se convocó a una asamblea extraordinaria de agricultores y ganaderos del Valle del Cauca a la cual asistieron 182 delegados de todos los municipios del departamento, el ministro de Agricultura y Ganadería, el gobernador y el secretario departamental de Agricultura y Ganadería. En ella, la Sociedad pudo "elevar el clamor del gremio antes las autoridades y ante la sociedad misma, por los vejámenes y atropellos de que es víctima” (SAG, abril, 1957, p. 7), entre ellos, el cobro del 4x1 000 para la CVC. Las críticas a la organización administrativa y dirección técnica de la $\mathrm{CVC}-\mathrm{y}$ su vinculación a la oficina de ingenieros de la que hace parte David Lilienthal- son numerosas. Entre varias consideraciones, se criticó que las obras a ejecutar priorizadas por la Corporación, como la construcción de embalses e hidroeléctricas, son excesivamente costosas y no corresponden con las urgencias económicas actuales del país para sugerir finalmente una revisión total de sus programas entre los cuales se debe dar prelación a un proyecto de colonización y parcelación 33

Además de solicitar al gobierno central la supresión del impuesto del 4x1 000 y el congelamiento de los avalúos catastrales, de los cuales dependía el monto del primero, la asamblea demandó:

\footnotetext{
${ }^{32}$ La habilitación de 6000 fanegadas de terrenos anegadizos, merced a la apertura de un canal de desecación de 27 kilómetros a finales de 1956 que regulaba las aguas de los ríos Frayle, Párraga, El Bolo y Aguablanca, y que conformaban la llamada ciénaga El Toro en los municipios de Candelaria y Palmira, había sido anunciada con beneplácito por la Revista Agrícola y Ganadera como una de las obras indirectas del Plan Lilienthal.

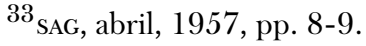


Que [...] las obras de irrigación y desecación del Valle del Cauca se realicen por intermedio de la oficina de Valorización de la Gobernación del departamento, para lo cual los agricultores y ganaderos estamos listos a sufragar los gastos proporcionales que impliquen dichas obras, en la medida que vayan beneficiando la planicie vallecaucana en sus respectivas propiedades (SAG, abril, 1957, p. 9).

Con esto, la Sociedad pretendía asegurar un mayor control sobre la ejecución de la Corporación si se tiene en cuenta que la Gobernación solía estar en manos de una dirigencia política y económica vinculada a la Sociedad de Agricultores del Valle y el Comité de Ganaderos.

Amparados en el desprestigio del régimen depuesto, la Sociedad de Agricultores del Valle y el Comité Departamental de Ganaderos se dirigieron a la Junta Militar de Gobierno donde denunciaron los exagerados gastos en la CVC y solicitaron que no se tomara ninguna decisión definitiva en cuanto al Plan Lilienthal, no solo por la naturaleza transitoria de la Junta -lo cual la inhabilitaba para tomar medidas de tanta trascendencia- sino también por el "acento totalitario y de tinte centralista" con que se impuso el Plan. Asimismo, proponen que se reorienten los esfuerzos para superar la crisis de producción de alimentos por medio de crédito barato, acceso a maquinaria, implementos, drogas veterinarias, etc., a precios razonables, y que se prescinda de nuevas plantas eléctricas por ya tener suficiente oferta energética en la región. Por último, piden "Que se suspenda la vigencia de los actos oficiales que crearon y organizaron el Plan Lilienthal o Corporación Autónoma Regional del Cauca, mientras el Congreso de la República estudia todo lo referente a dicha institución. En consecuencia, debe procederse a la liquidación de esa entidad y al licenciamiento de su personal" (sag, julio, 1957, pp. 12-13).

La campaña contra el Plan Lilienthal y el impuesto del 4x1 000 es intensa y ocupa numerosas páginas de la Revista Agrícola y Ganadera durante 1957: memorándums, cartas y artículos en los que se reiteran críticas casi virulentas y se exige la supresión del gravamen y de la cvc, además de la reorientación de los recursos destinados a la ejecución del Plan 34

Como acciones determinantes, los agricultores y ganaderos instauran, finalmente, demandas ante la Corte Suprema de Justicia y el Tribunal de lo Contencioso Administrativo de Cali solicitando la derogación del gravamen, al tiempo que obtienen de la Procuraduría General de la Nación concepto en el que se declaran inexequibles los decretos que creaban el impuesto del 4x1 000 "por ser lesivo de la Constitución, violatorio de las leyes y contrario a los fundamentos esenciales de la democracia" (sAG, julio, 1957, pp. 12-13; diciembre, 1957 p. 19). Asimismo, en los últimos meses de 1957, la Junta Militar aprobó disposiciones por las cuales amplió los recursos de la Caja de Crédito Agrario destinados a los agricultores, lo que atribuyó el presidente de la Sociedad, González Piedrahita, a que "la obcecación electrificadora ha sido desalojada de la mente de los gestores de la cosa pública. [Y por supuesto, a]... las tenaces gestiones adelantadas por esta Sociedad" (sAG, diciembre, 1957, p. 16). Además, el ejecutivo nacional tomó medidas que limitaron la autonomía de la CVC, en sintonía con las críticas de la Sociedad de Agricultores y el Comité de Ganaderos del Valle quienes reprocharon que una entidad con facultades de recaudo no tuviera obligación de rendir cuentas públicamente. En diciembre del mismo año, el Tribunal del Contencioso Administrativo profirió auto de suspensión de los decretos del 4x1 000. Al dar cuenta de todas estas

\footnotetext{
${ }^{34}$ SAG, agosto, 1957 , pp. 10-21; septiembre, 1957, pp. 8, 11-20; octubre, 1957, pp. 12-13; diciembre, 1957, pp. 821.
} 
nuevas situaciones favorables a los afiliados de la Sociedad y el Comité Ganadero, Ernesto González Piedrahita agradeció su concurso "sin el cual seguramente no habríamos alcanzado el éxito que motiva nuestra congratulación” (sAG, diciembre, 1957, p. 20).

En octubre de 1958, Camilo Molina Ossa, presidente del Comité Departamental de Ganaderos, en informe rendido a la Asamblea General de dicha entidad, enumeró los logros alcanzados por las agremiaciones respecto al Plan Lilienthal: postergación de los proyectos de electrificación, congelación de avalúos catastrales por cinco años y entrega de su manejo al Instituto Geográfico Agustín Codazzi, además de la exoneración del impuesto del 4x1 000 a minifundios cuyo patrimonio no excediera los 50000 pesos ${ }^{35}$ De esta manera, nuevamente, agricultores y ganaderos lograban, si no derrotar, al menos neutralizar las imposiciones tributarias derivadas de los proyectos de fomento de la productividad agrícola de origen gubernamental.

\section{La oposición a la Reforma Agraria}

Bejarano (1985) señala los factores que confluyeron para presionar la iniciativa de Reforma Agraria que empieza a discutirse a finales de la década de 1950 durante el gobierno de Alberto Lleras; entre ellos, principalmente, las recurrentes invasiones de tierras en algunas zonas del país y la persistente ineficiencia productiva del campo. La discusión se dio en el seno del Comité Agrario Nacional, entidad ad hoc que reunía distintas tendencias y gremios y cuya propuesta de Reforma Social Agraria fue presentada por el gobierno ante el Congreso como proyecto de ley. El documento final -sancionado en diciembre de 1961 luego de arduas y numerosas discusiones en el legislativo- terminó por contener varias modificaciones de la propuesta original (Bejarano, 1985, pp. 287-290).

La Sociedad de Agricultores del Valle y el Comité Departamental de Ganaderos apenas habían terminado su oposición al Plan Lilienthal y la CVC cuando se dedicaron a la tarea de incidir en los debates relacionados con la Reforma Agraria. Agricultores y ganaderos decidieron poner en la opinión pública nacional mayor énfasis en la urgencia del aumento de la productividad del campo que en la distribución de la propiedad, esto cada vez que señalaban y debatían las necesidades del país que sustentaban la iniciativa de la reforma. Así dijo Ernesto González Piedrahita antes de ser sancionada la ley:

Parto del supuesto de que la enmienda legislativa en proyecto persigue como finalidad primordial el aumento de la productividad agropecuaria, imperiosamente reclamada por la desnutrición de nuestro pueblo, así como por la necesidad de fomentar renglones de exportación sucedáneos del café en la balanza de pagos internacional (sAG, noviembre, 1960, p. 8).

Esta perspectiva tenía la bondad de ofrecer a los grandes propietarios de la región un lugar desde el cual refutar buena parte del articulado de la propuesta de ley. En efecto, una parte considerable de tierras en el Valle del Cauca ya estaba incorporada a un sistema productivo de gran eficiencia en el que se hacía uso intensivo de maquinaria, fertilizantes, herbicidas y en general, de asistencia técnica, por lo que su función social como productora de alimentos y generadora de riqueza nacional sería indiscutible. Las demás tierras cultivadas que no llegaban a dar los rendimientos deseados se mantenían así a causa de la "falta de técnica y carencia de orientación oficial"

${ }^{35}$ SAG, octubre-noviembre, 1958, p. 13. 
(sAG, abril, 1959, p. 9). En cuanto a la entrega de tierras a quienes no eran propietarios, se apoyaba la Sociedad en cifras de la CEPAL para sustentar que existían en Colombia más de 70 millones de hectáreas de baldíos aprovechables por lo que "no puede el Estado invocar título alguno en cuyo nombre haya de justificarse el desplazamiento de los actuales labradores [...]" (saG, noviembre, 1960, p. 9). Así, la Sociedad fue totalmente favorable a una política que, de hecho, ya se venía implementando: de colonización, parcelación, irrigación y fomento agrícola dirigida por la Caja de Crédito Agrario.

Nuevamente, la propuesta de creación de un impuesto, esta vez del 1x1 000 del avalúo catastral, es asumida como un castigo al trabajo de los hombres del campo que cargan sobre sus hombros la responsabilidad de pesadas contribuciones al Estado y los conduce a la ruina definitiva. Aunado a esto, los agricultores del Valle critican la creación de una inmensa burocracia dedicada a la implementación de la Ley:

¿No sería mejor que el proyecto de ley estatuyera en lugar de penas, medidas coercitivas y burocracia inútil, demostraciones prácticas sobre la manera como se puede aumentar la producción por medio de enseñanzas y creación de fincas pilotos, donde pueda demostrarse a la gente campesina que con métodos técnicos y económicos se aumenta la producción y por tanto el rendimiento de las fincas, como lo hemos venido proponiendo desde hace mucho tiempo? (sAG, abril, 1959, p. 14).

La Sociedad reprocha el uso despectivo y generalizado tanto en documentos oficiales como en la opinión pública de las palabras terrateniente y latifundio, cuando sus actividades y usos cumplen la función social y económica orientada a la producción que dice buscar el proyecto de ley. Se queja, también, de que solo se afecte a la propiedad rural y no se toque a la industria, el comercio y la propiedad urbana 36

Aprobada la Reforma Social Agraria a finales de 1961, Alfonso Jaramillo Arango, entonces presidente de la Sociedad de Agricultores del Valle, lamentó la poca influencia que tuvo este gremio en su discusión y señaló -con cierta resignación- que el país entró en un nuevo régimen para el cual debían todos prepararse ya que de su implementación dependía la entrega de importantes ayudas extranjeras como las prometidas en la Alianza para el Progreso de los Estados Unidos 37

Las resoluciones a inicios de 1963 del Instituto Colombiano para la Reforma Agraria (INCORA), que autorizaban la adquisición de predios en el norte del Valle para adelantar un plan de parcelaciones y las consiguientes invasiones de algunas propiedades por colonos, no solo reactivaron sino que cristalizaron los publicitados temores de los terratenientes:

Existe el otro objetivo de dar tierras a quienes las desean y no las tienen y crear empleos para los desocupados. ¿Se va a cumplir esto expropiando tierras ampliamente explotadas como las del Valle del Cauca? Es bueno saber que en todas las expropiaciones que se van a verificar en el Norte del Valle, se pueden colocar solamente 700 personas. ¿Es esto una solución? ¿Lograrán estas gentes pobres redimir esas tierras caras durante toda su vida? ¿O se van a hacer nuevos esclavos de la tierra? (sAG, marzo-abril, 1963, p. 6).

La Sociedad de Agricultores del Valle, al considerar ilegales las resoluciones conforme al espíritu de la Ley 135, convocó junto con la SAC a una reunión con el ministro de Agricultura y el director del INCORA, la cual no tuvo los resultados esperados; así que, primero vía telegrama y luego en reunión directa con el presidente de la República, Guillermo León Valencia, el gremio anunció

${ }^{36}$ SAG, diciembre, 1960 , p. 16.

${ }^{37}$ SAG, noviembre-diciembre, 1961 , p. 9. 
la inminente "desaparición del régimen de propiedad privada de continuar actuación del INCORA" (sAG, junio, 1963, p. 7) y luego compartió su angustia por la ruptura "de todos los fundamentos de nuestra organización democrática” de prosperar sus planes en el norte del departamento:

Advertimos al Sr. Presidente que los agricultores del Valle no están coaligados contra la Reforma Agraria, sino que los encargados de aplicarla la están deformando para afectar seriamente la productividad agrícola y la paz social. Anotamos también nuestra protesta por haber tomado al Valle para un experimento de comunicación de las tierras y este no se haya verificado en las cercanas a Bogotá, donde hay mayor presión demográfica, pero también mayores influencias. (SAG, junio, 1963, p. 28)

Sin duda, los atropellos del INCORA, al modo de ver de agricultores y ganaderos regionales, tenían origen, en parte, en la intención deliberada del centralismo bogotano de debilitar las regiones que sostenían un creciente ritmo de creación de riqueza. Por todo lo anterior, se hizo cada vez más evidente la urgente necesidad de una organización gremial más sólida y coordinada que se concretó finalmente en la fusión de la Sociedad de Agricultores del Valle y el Comité departamental de Ganaderos. La nueva Sociedad de Agricultores y Ganaderos (SAG) fue formalizada en agosto de 1963 en una atmósfera de tensión con el gobierno central. Dirigió desde el primer momento sus acciones en defensa de los propietarios rurales del norte del Valle y se apropió, con tal fin, del naciente Plan Azucarero del Valle, promovido por los ingenios y el capital industrial del departamento. Así pues, se buscó corregir la "errada aplicación de la Reforma Agraria" que adelantaba el Instituto Colombiano de la Reforma Agraria, oponiéndole un ambicioso programa de producción de caña que incorporaría 300000 hectáreas y crearía 140000 empleos, invitando a los propietarios de la zona entre Bugalagrande y Cartago a asociarse al mismo 38

Esta coyuntura significó en el mediano plazo la presencia cada vez más formal del sector azucarero en esta nueva fase de la SAG. En adelante, a los nombres de los representantes de agricultores y ganaderos se sumarán los de los dirigentes de ASOCAÑa y otros ejecutivos del sector azucarero, cada vez que se informaba de las comisiones enviadas a Bogotá delegadas para gestionar e influir en decisiones del gobierno central. La Revista Agrícola y Ganadera dedicó durante estos años gran parte de sus contenidos a temas de producción y política azucarera, identificando sus orientaciones y ejecutorias con la agroindustria de la caña de azúcar, algo impensable apenas pocos años antes.

\section{Conclusiones}

El análisis de las estrategias y comportamiento de la SAG frente a tres proyectos del gobierno (la misión del Banco Mundial liderada en 1950 por Lauchlin B. Currie, la aplicación del programa de inversiones propuesto por David Lilienthal en 1954, y la Ley 135 de 1961 o Ley de Reforma Agraria) evidenció cómo las acciones y posiciones de los líderes de la SAG -en relación con el desarrollo agrícola- determinaron la configuración de una lógica de la influencia que buscaba oponerse a los intentos de reforma del sector agrícola en el Valle del Cauca. Esta forma de comprender el desarrollo de su sector los instaló en una posición de conflicto -más que de colaboración- con las iniciativas del gobierno central y regional. Como expresión del empresariado organizado, la sAG desarrolló una estrategia de influencia que le permitió proteger los intereses de sus afiliados, pero que a largo plazo la llevó a perder liderazgo al interior del empresariado regional y participación en el diseño de políticas que beneficiaran a todo el sector. Esta situación se hizo evidente con

${ }^{38}$ SAG, julio-agosto, 1963, pp. 5-6. 
la fragmentación que provocó la creación de nuevas asociaciones gremiales al interior del sector agropecuario - como ASOCAÑA-, pero sobre todo, a partir de la década de 1990 cuando comenzaron a ser obvios los problemas financieros y de legitimidad que la organización discutía en sus reuniones de junta directiva.

En un contexto más general, como argumenta Rettberg (2001) y Junguito (2019), los gremios han sido actores importantes en la canalización de privilegios hacia sus representados en aspectos como: la provisión de licencias, permisos, exenciones tributarias y manejo de recursos púbicos por medio de la intervención en políticas sectoriales. Aunque después de la década de 1990 los gremios han perdido influencia y efectividad en el desarrollo de sus agendas (Rettberg, 2001a, 2001b, 2005; Urrego, 2001), este artículo demostró la importancia de las asociaciones gremiales en el desarrollo empresarial colombiano (Junguito, 2019). En particular, a partir del caso de la SAG, se analizó la importancia de la lógica de la influencia en el comportamiento gremial colombiano, además de la existencia -aunque marginal- de la lógica de los servicios. En este sentido, aporta una mirada más amplia sobre la dinámica de los gremios y avanza sobre la mayoría de los estudios (Cárdenas, 1990; De Lombaerde, 2000; Urrego, 2001) que se focalizan en analizar los gremios principalmente en temas de política pública y su influencia en la configuración institucional del país. Los trabajos de Urrutia (1983), Machado y Samacá (2000) y Losada (2000) tienen en común que estudian las asociaciones gremiales desde una perspectiva neoinstitucionalista, así como las características y dificultades de la acción gremial desde la Teoría de la Acción Colectiva desarrollada por Olson (2003). Otro grupo de estudios, menos numeroso y sin una perspectiva teórica explicita, se ha concentrado en desarrollar análisis de gremios particulares en diferentes sectores: para el agropecuario, la industria y el comercio destacan trabajos sobre la Federación Nacional de Cafeteros (Saether, 1999), la Asociación Nacional de Industriales ANDI (Sáenz, 1992), la Federación Nacional de Comerciantes fenalco (Rodríguez, 1996), y acopI (Guevara, Piza y Bravo, 2006; Pallares, 2002).

Esta muestra de investigaciones contrasta con el peso y la importancia de las organizaciones gremiales en la economía política del país durante el siglo xx. Por ejemplo, mientras en la década de 1950 puede estimarse la existencia de 22 gremios, hacia finales de siglo su número creció alrededor de 1036 por ciento (Losada, 2000, p. 31). Así, en el año 2000 existían en Colombia 228 gremios que actuaban en diferentes sectores y tenían diferentes alcances (Losada, 2000, p. 24). De estos, solo 5 eran considerados gremios cúpula, lo que es indicativo de la alta fragmentación de la representación empresarial y, en su mayoría, pertenecían al sector agropecuario.

Este estudio también confirma trabajos previos que muestran la preponderancia de la lógica de la influencia en el comportamiento gremial colombiano (Arévalo y Rodríguez, 2001; Berdugo, 2000; Rodríguez, 1996; Saether, 1999), la cual se ha mantenido en un terreno más reactivo que estratégico en el desarrollo de sus sectores. Esto, aunado -o en consecuencia- a la alta fragmentación gremial, ha generado un problema evidente que ha incidido en contra de la capacidad de coordinación y desarrollo de algunos sectores del país. Con todo esto, es evidente que todavía queda desarrollar más investigación sobre las formas de organización del empresariado colombiano.

Finalmente, es importante plantear algunas recomendaciones de política pública que surgen de este trabajo. En el caso de la SAG, es evidente que, aunque la lógica de la influencia fue la estrategia dominante, los líderes de este gremio también intentaron desarrollar tácticas orientadas hacia la provisión de bienes públicos a sus asociados. Sin embargo, la lógica de los servicios estuvo restringida por dos factores: una concepción del desarrollo agropecuario que se oponía al cambio tecnológico y a las iniciativas que provenían del gobierno central enfocadas en reformar y mo- 
dernizar el sector, así como por las recurrentes restricciones de recursos tanto financieros como científico-tecnológicos. Por ello, es importante que los gobiernos no solo apoyen la creación de entidades gremiales a través de las cuales se pueda institucionalizar las relaciones con el empresariado, sino también impulsen la creación de fondos provenientes para lograr la estabilidad de los sectores, incidan en las concepciones que estos actores tienen sobre el desarrollo futuro de sus industrias e impongan restricciones para el uso de los recursos que privilegien las inversiones en bienes públicos a sus asociados.

\section{LISTA DE REFERENCIAS}

Arévalo, D. y Rodríguez, O. (2001). Gremios, reformas tributarias y administración de impuestos en Colombia. Bogotá: Universidad Externado de Colombia.

Batero, J. (2018). Asociación de productores y fabricantes en el Valle del Cauca 1932-1940. En H. Sánchez y A. Santos (eds.), Buscando el crecimiento económico. Mercado de factores, industrialización y desarrollo económico en Cali y el Valle del Cauca 1900-1950 (pp. 71-102). Cali: Universidad del Valle.

Bejarano, A. (1985). Economía y poder: la SAC y el desarrollo agropecuario colombiano 1871-1984. Bogotá: $S A C$ /Fondo Editorial CEREC.

Bennett, R. J. (1995). The Logic of Local Business Associations: An Analysis of Voluntary Chambers of Commerce. Journal of Public Policy, 15(3). Dor: 10.1017/S0143814X00010047

Bennett, R. J. (1999). Explaining the Membership of Sectoral Business Associations. Environment and Planning A: Economy and Space, 31(5). Dor: 10.1068/a310877

Berdugo, E. (2000). Los gremios de la producción y del comercio en Colombia y su influencia en la determinación de la política económica 1944- 1994 (Maestría). Universidad Nacional de Colombia.

Cárdenas, J. (1990). La organización gremial y el desarrollo cafetero colombiano. Revista Nacional de Agricultura, Sociedad de Agricultores de Colombia (sAC), Marzo.

Collins, C. D. (1981). La prensa y el poder político en Colombia: Tres ensayos (Vol. 2). Cali: Universidad del Valle/CiDSE.

Collins, C. D. (2018). Formación de un sector de clase social: La burguesía azucarera en el Valle de Cauca durante los años treinta y cuarenta. Historia y Espacio, 9. Dor: 10.25100/hye.v0i9.6792

De Lombaerde, P. (2000). La economía política de la política comercial en Colombia: la influencia de los gremios en la formulación de la política comercial. Colombia Internacional, Enero(48). DoI: $10.7440 /$ colombiaint 48.2000 .03

Dixon, L. (2006). The Representative Role of Regional Business Associations: The Engineering Employers' Federation Northern Association in North East England. Regional \&o Federal Studies, 16(2). DoI: 10.1080/13597560600652056

Eisenhardt, K. M. (1989). Building Theories from Case Study Research. Academy of management review, 14(4).

Eisenhardt, K. M. y Graebner, M. E. (2007). Theory Building from Cases: Opportunities and challenges. Academy of management journal, 50(1).

Ekbladh, D. (2002). "Mr. TVA": Grass-Roots Development, David Lilienthal, and the Rise and Fall of the Tennessee Valley Authority as a Symbol for u.s. Overseas Development, 1933-1973. Diplomatic History, 26(3). DoI: 10.1111/1467-7709.00315

Guevara, L., Piza, F. y Bravo, C. (2006). La pyme y sus aportes al desarrollo de Colombia: La historia de ACOPI 1951-2006. Bogotá: ACOPI. 
Junguito, R. (2019). El papel de los gremios en la economía colombiana. Revista Desarrollo y Sociedad, 82.

Lanzalaco, L. (1992). Coping with Heterogeneity: Peak Associations of Business within and across Western European nations. En J. Greenwood, J. R. Grote, y K. Ronit (eds.), Organized interests and the European Community (pp. 173-205). London: Sage.

Lanzalaco, L. (2008). Business Interest Associations. En G. G. Jones y J. Zeitlin (eds.), The Oxford Handbook of Business History. London: Oxford University Press.

Londoño, J. (2018). La Cámara de Comercio de Cali. Una institución en el marco de una economía regional, 1910-1948. En E. Carporalli y A. Echeverry (eds.), Poder y ciudad en Cali. Hacia la construcción de un orden urbano. 1910-1950 (pp. 95-140). Cali: Universidad ICESI/Universidad del Valle.

López, L. (1995). Intervencionismo de estado y economía en Colombia (2a ed.). Bogotá: Universidad Externado de Colombia.

Losada, L. (2000). Los gremios empresariales en Colombia en los inicios del siglo XXI. Bogotá: Pontificia Universidad Javeriana.

Machado, A. y Samacá, H. (2000). Las organizaciones del sector agropecuario: un análisis institucional. Bogotá: Colciencias.

March, J. G. (1962). The Business Firm as a Political Coalition. The Journal of Politics, 24(4). Recuperado de http://www.jstor.org/stable/2128040

March, J. G. y Simon, H. A. (1958). Organizations. Oxford: Wiley.

Medina, I. (2016). Are Business Associations Involved in Regional Politics? Evidence from Spain and the United Kingdom. European Urban and Regional Studies, 23(3). Dor: 10.1177/0969776413513603

Mejía, E. (2003). Ciro Molina Garcés y Carlos Duran Castro: gestores y científicos en el desarrollo agropecuario del Valle del Cauca. En C. Dávila y L. Guevara (eds.), Empresas y empresarios en la historia de Colombia. Siglos XIX y Xx. Una colección de estudios recientes (pp. 1190-1212). Bogotá: Universidad de los Andes.

Ocasio, W. (1997). Towards an Attention-Based View of the Firm. Strategic Management Journal, 18. Recuperado de http://www.jstor.org/stable/3088216

Offe, C. y Wiesenthal, H. (1980). Two Logics of Collective Action: Theoretical Notes on Social Class and Organizational Form. Political power and social theory, 1(1).

Olson, M. (2003). The Logic of Collective Action: Public Goods and the Theory of Groups. Cambridge: Harvard University Press.

Palacios, M. (2011). ¿̇De quién es la tierra? Propiedad, politización y protesta campesina en la década de 1930. Bogotá: Universidad de los Andes/Fondo de Cultura Económica.

Pallares, Z. (2002). ACopi: el gremio de la Pyme. Cincuenta años de historia 1952-2001. En C. Dávila (ed.), Empresas y empresarios en la historia de Colombia. Siglos XIX-XX. Una colección de estudios recientes. Bogotá: Universidad de los Andes.

Pfeffer, J. y Salancik, G. R. (2003). The External Control of Organizations: A Resource Dependence Perspective. United States: Stanford University Press.

Rettberg, A. (2001a). Dos crisis, dos desenlaces: retos realidades del empresario organizado colombiano en los años cincuenta y noventa. Revista de Estudios Sociales, 8.

Rettberg, A. (2001b). The Dilemmas of Business Representation: The Uneasy Relationship of Economic Groups (EGs) and Business Associations in Colombia (1994-1998). Presentado en Latin American Studies Association, Washington, DC. 
Rettberg, A. (2003). Entre el cielo y el suelo: una mirada crítica a los gremios colombianos. En A. Mason y L. J. Orjuela (eds.), La crisis política colombiana: más que un conflicto armado y un proceso de paz (pp. 253-257). Bogotá: Ediciones Uniandes/Alfaomega Editores.

Rettberg, A. (2005). Business Versus Business? Grupos and organized business in Colombia. Latin American Politics and Society, 47(1).

Rodríguez, O. (1996). Interés gremial y regulación estatal. La formación de la Federación Nacional de Comerciantes 1945-1970. Anuario Colombiano de Historia Social y de la Cultura, 23.

Sáenz, E. (1992). La ofensiva empresarial: Industriales, políticos y violencia en los años 40 en Colombia. Colombia: Universidad Nacional de Colombia/ces.

Saether, S. (1999). Café, conflicto y corporativismo una hipótesis sobre la creación de la Federación Nacional de Cafeteros de Colombia en 1927. Anuario colombiano de historia social y de la cultura, 26.

Schmitter, P. C. y Streeck, W. (1981). The Organization of Business Interests: A Research Design to Study the Associative Action of Business in the Advanced Industrial Societies of Western Europe (Discussion papers, n.13). Berlin: International Institute of Management/Labour Market Policy.

Schneider, B. (2002). ¿Why is Mexican Business so Organized? Latin American Research Review, $37(1)$.

Schneider, B. R. (2004). Business Politics and the State in Twentieth-Century Latin America. New York: Cambridge University Press.

Simon, H. A. (1948). Administrative Behavior: A Study of Decision-making Processes in Administrative Organizations. United States: Macmillan.

Simon, H. A. (1956). Rational Choice and the Structure of the Environment. Psychological review, $63(2)$.

Simon, H. A. (1972). Theories of Bounded Rationality. Decision and organization, 1(1).

Streeck, W., Grote, J. R., Schneider, V. y Visser, J. (2006). Governing Interests: Business Associations Facing Internationalization. London/New York: Routledge.

Thompson, E. (2002). La lógica de la historia. En Obra esencial. Miseria de la Teoría. Barcelona: Crítica.

Traxler, F. y Huemer, G. (eds.). (2007). Handbook of Business Interest Associations, Firm Size and Governance: A Comparative Analytical Approach. London/New York: Routledge.

Urrego, A. C. (2001). Las organizaciones gremiales del sector agrario y su influencia en la política sectorial. Un análisis en el contexto de la transición económica. Revista Colombiana de Sociología, $6(1)$.

Urrutia, M. (1983). Gremios, política económica y democracia. Bogotá: Fondo Cultural Cafetero.

Waarden, F., van. (1992). Emergence and Development of Business Interest Associations. An Example from The Netherlands. Organization Studies, 13(4). Dor: 10.1177/017084069201300402

Zuluaga, J. C. (2009). La historiografía económica sobre el Valle del Cauca, siglos xix y xx. Temas, espacios y tiempos: Una aproximación cuantitativa. HiSTOReLo. Revista de Historia Regional y Local, 1(2). DOI: 10.15446/historelo.v $\ln 2.10342$

Zuluaga, J. C. (2012). Historiografía empresarial e industrial sobre el Valle de Cauca, 1950-2007. HiSTOReLo. Revista de historia regional y local, 4(8). 


\section{Otras fuentes}

SAG Sociedad de Agricultores y Ganaderos. (1940-1966). Revista Agrícola y Ganadera. Plan Lilienthal, 1954.

\section{Archivos}

Actas de Junta Directiva, 1989-2014, Archivo Histórico de la Sociedad de Agricultores y Ganaderos (sAG), Valle del Cauca, Colombia.

Actas de Asamblea de Socios, 1985-2013, Archivo Histórico de la Sociedad de Agricultores y Ganaderos (sAG), Valle del Cauca, Colombia.

Correspondencia, 1963-2000, Archivo Histórico de la Sociedad de Agricultores y Ganaderos (sAG), Valle del Cauca, Colombia.

\section{Anexo 1.}

Categorías EMERGENTES DEL aNÁLISIS DE AGTAS DE LA JUNTA DiREGTIVA DE LA SC

SEGURIDAD RURAL Y ORDEN PÚBLICO

Discusiones, informes y/o planificación de reuniones, gestiones y/o coordinación con autoridades militares (Tercera Brigada), de policía, DAs, entre otras, relacionadas con delincuencia común (abigeato, atraco a fincas), guerrilla, salvoconductos de armas, secuestros, extorsiones, obtención y gestión de recursos, y estrategias de defensa (jurídica, comunicaciones, cooperativas, cursos de prevención).

PROPIEDAD Y TENENCIA DE LA TIERRA

Discusiones e informes sobre estrategias y acciones en defensa de intereses propietarios frente a pretensiones de otros actores como el INCORA, comunidades campesinas e indígenas.

PROBLEMAS AMBIENTALES

Informes, discusiones y gestiones tendientes a resolver afectaciones originadas en situaciones ambientales, tales como necesidad de manejo de cuencas (caudales, reforestación e impactos de minería) y emergencias invernales, que afectan actividades de producción agropecuaria.

PROCESOS DE PAZ

Informes y discusiones sobre diálogos de Paz con insurgencia; invitaciones e iniciativas de otros actores. 
CATEgorías EMERgENTES DEL ANÁLISIS DE ACTAS DE LA JUNTA DIRECTIVA DE LA SG

RELACIONES INTERORGANIZACIONALES

Invitaciones, informes de asistencia, preparativos de/a: conferencias, congresos, foros, asambleas, ferias, seminarios, aniversarios, viajes, homenajes, distinciones, cenas, etc.; eventos organizados por otras entidades o en conjunto con otras entidades. Acoge, en general, acercamientos a otras entidades con objetivos gremiales y mediaciones en situaciones conflictivas.

RELACIONES POLÍTICAS

Saludos a nuevos funcionarios públicos (civiles o militares), organización, discusiones e informes de/sobre reuniones con funcionarios (alcaldes, concejales, gobernadores), dirigentes políticos (representantes, senadores, candidatos a cargos de elección popular) y agregados diplomáticos. Otras acciones (comunicaciones, decisiones) que denotan intención gremial por sostener posturas y relaciones frente a/con el entorno político/institucional.

ACTIVIDADES PROSPECTIVAS AGROPECUARIAS

Informes, discusiones, gestiones y diversas actividades en torno a estudios/proyectos de planeación en el sector agropecuario, posibilidades de nuevos cultivos/productos, perspectivas de desempeño del sector (o subsectores), o de evaluación de impacto de gravámenes; liderados por la SAG, por otros actores (Ministerio o Secretaría de Agricultura, alcaldías, organismos intersectoriales, empresas u otras entidades gremiales), o en conjunto SAG-otros actores. En muchos casos estas actividades están orientadas a la obtención de recursos para la Sociedad.

OBTENCIÓN DE BENEFICIOS DE ENTIDADES/INSTITUCIONES LOCALES O REGIONALES Informes y discusiones sobre gestiones adelantadas o en curso, ante entidades públicas o privadas que buscan favorecer (o neutralizar perjuicios) a la SAG, al sector agropecuario en general, o a algún subsector en particular en asuntos tales como: reparación de infraestructura (caminos, puentes), distritos de riego (planes de riego, canalización, control de caudales), impuestos (catastro, predial, industria y comercio, tarifas por uso de aguas, valorización), facilidades para trámites y obtención de recursos (a través de la realización de estudios, proyectos, consultorías, cursos de capacitación, convenios, inversiones).

OBTENCIÓN DE BENEFICIOS DE ENTIDADES/INSTITUCIONES NACIONALES 
CATEgORÍAS EMERGENTES DEL ANÁLISIS DE ACTAS DE LA JUNTA DIRECTIVA DE LA SG

Informes y discusiones sobre gestiones adelantadas o en curso, ante entidades públicas o privadas que buscan favorecer (o neutralizar perjuicios) a la SAG, al sector agropecuario en general, o a algún subsector en particular en asuntos tales como: impuestos (incentivos, catastro, valorización, IVA), obtención de recursos (a través de la realización de consultorías, convenios), mejoramiento de condiciones de crédito y de precios de comercialización.

ACTUALIZACIÓN Y ANÁLISIS COYUNTURA AGROPECUARIA

Informes, presentaciones, discusiones y análisis adelantados por socios individuales o gremiales de la SAG, o funcionarios de otras entidades, sobre asuntos agropecuarios tales como: comportamiento de cultivos, costos de producción, precios de sustentación, situación ganadera, crédito y aseguramiento del sector, regulaciones e impactos de importaciones (apertura económica) y estrategias de mitigación de las mismas, exportaciones, investigación científica, situación y/o misión entidades del sector, situaciones agropecuarias en otros países o regiones, y nuevos servicios.

ESTRATEGIAS DE INTERVENCIÓN INSTITUCIONAL

Informes y discusiones acerca de actividades (envío de comunicaciones, reuniones con otros actores) que denotan clara intención de influir, impugnar o intervenir procesos y decisiones de formulación o aplicación de políticas públicas (ej. Apertura económica e impacto de importaciones) o normatividades que afectan al sector. Dichas actividades pueden ser adelantadas por la SAG o en conjunto con otros sectores y/o entidades gremiales.

Es importante diferenciar esta categoría de las núm. 8 y 9 enfatizando que no acoge las gestiones concretas para obtener beneficios inmediatos y tangibles, sino las actividades tendientes a intervenir, influir o simplemente manifestar una postura clara, en la mayoría de los casos desde un nivel más político, por medio de la planeación y el despliegue de estrategias de acción coordinadas.

DINÁMICAS INTERNAS SAG

Informes y discusiones que dan cuenta de establecimiento de planes y estrategias de sostenimiento y financiación (ej. Construcción sede propia, incremento de afiliaciones), afirmación y/o revisión de objetivos misionales y gremiales, fijación de funciones y metas inmediatas, reorganización de estructura de la Sociedad y desarrollos de mecanismos de gestión directiva (en presidencia y junta directiva).

REPRESENTACIÓN SAG EN OTRAS ENTIDADES 
CATEGORÍAS EMERGENTES DEL ANÁLISIS DE AGTAS DE LA JUNTA DIREGTIVA DE LA SC

Informes, discusiones y gestiones relativas a la escogencia, participación e intervención de miembros representantes de la Sociedad en cuerpos directivos o asambleas de otras entidades.

DIVULGACIÓN DE CONOCIMIENTOS Y SERVICIOS

Informes y discusiones relativas a la planeación y realización de actividades orientadas a la promoción de la imagen de la SAG ante la sociedad y su sector gremial a partir de la divulgación/socialización de conocimientos y servicios técnicos, científicos, legales, comerciales, financieros y culturales a través de iniciativas editoriales (manuales, revistas, boletines), formativas (cursos, seminarios, conferencias, foros), publicitarias y de negocios (ferias).

SEGUIMIENTO Y ANÁLISIS COYUNTURA POLÍTICO-ADMINISTRATIVA

Discusiones y análisis de acontecimientos de orden político y administrativo tales como: planeación, trámite y aprobación de reformas, proyectos de ley, decretos, tratados comerciales, discusión de presupuestos, políticas agropecuarias, dinámicas del poder ejecutivo. Estas actividades pueden preceder o ser simultáneas a aquellas en las que se discuten estrategias y gestiones de intervención (categorías 8, 9 y 11). 